Original Research Article

\title{
Knowledge, attitude and practice of haemovigilance amongst healthcare professionals in Nashik, Maharashtra, India
}

\author{
Prashant P. Shivgunde*, Smruti M. Besekar, Khushboo M. Bhojwani, Divya G. Bhojwani
}

\author{
University Research \\ Department, Maharashtra \\ University of Health Sciences, \\ Nashik, Maharashtra, India \\ Received: 15 March 2018 \\ Revised: 03 April 2018 \\ Accepted: 07 April 2018 \\ *Correspondence to: \\ Dr. Prashant P. Shivgunde, \\ Email: prashantshivgunde@ \\ gmail.com
}

Copyright: (C) the author(s), publisher and licensee Medip Academy. This is an openaccess article distributed under the terms of the Creative Commons Attribution NonCommercial License, which permits unrestricted noncommercial use, distribution, and reproduction in any medium, provided the original work is properly cited.

\begin{abstract}
Background: Haemovigilance Programme of India was launched in 2012 with the purpose to identify, analyse and learn the complications related to transfusion and blood donation, in order to avoid such complications in future. Though it is essential to identify the Adverse Transfusion Reactions (ATR) to reduce the incidence and make transfusion easier; there are rare reports available about knowledge, attitude, and practice (KAP) of Healthcare Professionals (HCP) for haemovigilance.

Methods: In this cross-sectional study, pre-validated questionnaire designed for assessing the KAP, the possible ways to improve transfusion reaction reporting and causes of underreporting were distributed among 220 Healthcare Professional (HCP) in Nashik, Maharashtra.

Results: The response rate of the study was 93\%. Amongst them 58\% HCP had poor knowledge while only $9 \%$ had good knowledge about haemovigilance. According to respondents, training to the $\mathrm{HCP}$, CME's, making reporting compulsory and launching of a toll-free helpline number will mark a milestone in improving transfusion reaction reporting. Legal liability issue and lack of time $\&$ knowledge were the main factors which discouraged them from reporting.

Conclusions: Overall, most of HCP in Nashik have a positive attitude towards transfusion reaction reporting but knowledge regarding the haemovigilance concept is poor and the majority of them never reported ATR. Hence, our study demands increased awareness and continued training to strengthen the haemovigilance system, especially ATR reporting.
\end{abstract}

Keywords: Adverse transfusion reactions, ATR, Haemovigilance, Transfusion reaction reporting, Underreporting

\section{INTRODUCTION}

Blood and blood product transfusion is a life-saving intervention. ${ }^{1}$ A transfusion reaction can be defined as any transfusion, having certain risks and any unfavourable event occurring in the patient during or after transfusion, for which no other reason can be found. ${ }^{2}$ Blood is categorized as a drug, as per the Drug and Cosmetic Act. ${ }^{3}$

However, there are risks of adverse events associated with the transfusion of blood and blood products to patients. The concept of safe blood transfusion gained attention in Europe aftermath of public outcry following the contaminated blood scandals and legal cases of the 1980s and 1990s. This created an immediate need for developing a surveillance system for transfusion safety. Now this surveillance system is commonly known by the name of Haemovigilance. ${ }^{4-7}$

The word "Haemovigilance" was coined in France in 1991 in analogy to the already existing term Pharmacovigilance. It is derived from the word Greek word "haema" means blood and the latin word "Vigilance" means watchful. According to the international haemovigilance Network, haemovigilance can be defined as "a set of surveillance procedures covering the whole transfusion chain (from the collection of blood and its components to the follow up of 
recipients), intended to collect and access information on unexpected or undesirable effects resulting from the therapeutic use of labile blood products and to prevent their occurrence or recurrence. ${ }^{6-10}$

In 1991, with the setup of blood transfusion committees in France a national haemovigilance was established. Later in 1998, European haemovigilance network was organized. Currently, on global scale an international haemovigilance network is functional, which evolved from European haemovigilance Network. The organization of haemovigilance system is dependent on traceability of blood and blood products from donors to recipients and vice versa, and on the monitoring, reporting, investigation and analysis of adverse events. The information thus generated through this system is a key to introduce required amendments in blood policies and guidelines that lead to increase safety and quality of the entire transfusion process. ${ }^{10,11}$

\section{Haemovigilance programme of India}

The Indian Pharmacopeia Commission (IPC), a ministry of Health and Family Welfare, Government of India in collaboration with National Institute of Biologicals, Noida has launched Haemovigilance Program in India on $10^{\text {th }}$ December 2012 as an integral part of the Pharmacovigilance Programme of India (PvPI). It is a centralized, structured program which coordinates various activities between blood bank, transfusion services, hospitals, healthcare, regulatory agencies and national health authorities. ${ }^{12}$ Haemovigilance Program of India (HvPI) was implemented across the country in 90 medical colleges in the first phase. The target of HvPI is grouped into three phases-initiation phase, expansion and consolidation phase and expansion and maintenance phase of the year 2012 to 2017 respectively.

The objectives of HvPI are to monitor transfusion reaction, create awareness amongst healthcare professionals, generate evidence based recommendation, advice CDSCO for safety related regulatory decisions, communicate findings to all key stakeholders and to create national and international linkages. There are currently 2760 blood banks in India, despite being so many blood banks, only 206 centres are enrolled under haemovigilance programme out of which only 71 centres are actively reporting and 2296 transfusion reaction have been reported till $2015 .^{13}$

Haemovigilance is an integral part of the treatment of diseases. Still, it is not widely practiced in Indian hospitals. In various studies, adverse transfusion reactions have been implicated as a leading cause of risk ranging from minor to life threatening. According to a study in France, there was a large increase in the number of reporting of transfusion reactions ranging from 1957 in between 20112015 to 16,050 adverse reactions in 2016. The incidence of reporting transfusion reactions in the South West Netherlands after introduction of the regional reporting system was estimated at $53 \%$.
The incidence of adverse transfusion reactions in India varies with studies which show incidences ranging from as low as $0.27 \%$ to as high as $1.05 \%$. Indian reports on adverse transfusion reaction monitoring have been very low. This may be because monitoring is still evolving. Unfortunately, in a country like India reporting of transfusion related adverse events are not mandatory. In addition, studies had reported underreporting by the medical staff and thus most of the minor adverse events do not come in attention; therefore, the exact incidences of various types of transfusion reactions are not known. ${ }^{14-18}$

Five years have passed since haemovigilance programme launched, though there is a continuous increase in Blood Bank participation in the program, it is an alarming need of an hour to increase the awareness regarding reporting of haemovigilance as a step towards safe blood transfusion and patient safety. Haemovigilance has developed and will continue to develop in response to the safety needs and such active influences need to be encouraged and fostered.

Without haemovigilance, it is impossible to definitively weigh the risk associated with transfusion and consequently difficult for healthcare professionals to assess the benefit/ risk ratio and counsel pre-transfusion patients accordingly. In order to improve the reporting rate, it is important to improve the knowledge, attitude and practice of the healthcare professionals with regard to the adverse transfusion reaction reporting and the haemovigilance.

This study will not directly benefit the participants, but their knowledge and practice will safeguard the wellbeing and healthcare of society. As understanding of the haemovigilance related KAP of the HCP is the highest standing determinants of HCP participation in programme implement, the above discussed study is conducted using the KAP model as a survey tool. ${ }^{19}$

\section{METHODS}

This was a cross-sectional study, which included data from the HCP in Nashik. Two Hundred and twenty sample size was calculated using formulae $n=4 p q / e^{2}$ where the proportion (p) was considered to be $50 \%$ and the allowable error (e) was taken $7 \%$ at $95 \%$ confidence interval. All the participants were selected using random consecutive sampling method.

The tool used for this study was pre-validated questionnaire which was validated by the same type of respondents through pilot study.

Close ended KAP questionnaire which includes 26 questions, out of these 5 questions for demographic details, 9 questions regarding knowledge, 6 for attitude towards reporting, 4 for practice, 1 for underreporting and 1 for possible ways to improve reporting of transfusion reaction were prepared. Before distributing the questionnaires, the subjects were informed about the purpose and the course 
of study and only after obtaining written informed consent; the subjects were recruited as per eligibility criteria.

The subjects, thus enrolled were offered the questionnaire and requested to return completely filled questionnaire within 30 minutes. The study was conducted in the period of February 2017 to August 2017.

\section{Statistical analysis}

The data from the collected questionnaires was added to the M.S Excel sheets and was calculated in percentage.

\section{RESULTS}

Our study showed $93 \%$ response rate out of the 220 eligible healthcare professionals involved in this study, only 184 returned their completely filled questionnaire. Among these respondents, 123 (66.84\%) were doctors, 58 $(31.52 \%)$ nurses, $3(1.63 \%)$, pharmacists.

About two thirds of the respondents, 125 (67.93\%), were females and $59(32.06 \%)$ were males, giving male to female ratio of 1: 2. Demographic details of the participants are summarized in Figure 1.

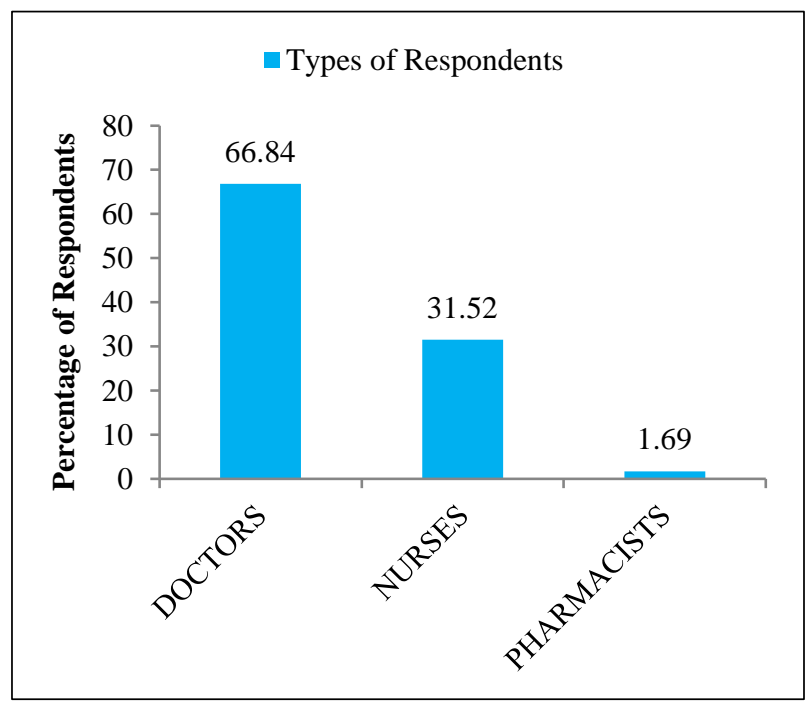

Figure 1: Details of the types of respondents.

While assessing the knowledge of healthcare professionals (Figure 2), it was found that $58 \%$ of HCP were not aware about haemovigilance program and transfusion reaction reporting while only $9 \%$ had a good level of knowledge.

A total of $80(43.48 \%)$ disagreed that reporting of each transfusion reaction is not essential. About 117 (63.59\%) respondents agreed that transfusion reaction reporting benefits patients. $88(47.83 \%)$ respondents strongly agreed that haemovigilance should be taught to HCP during their curriculum. $101(54.89 \%)$ agreed that transfusion reaction reporting is a professional duty (Figure 3).

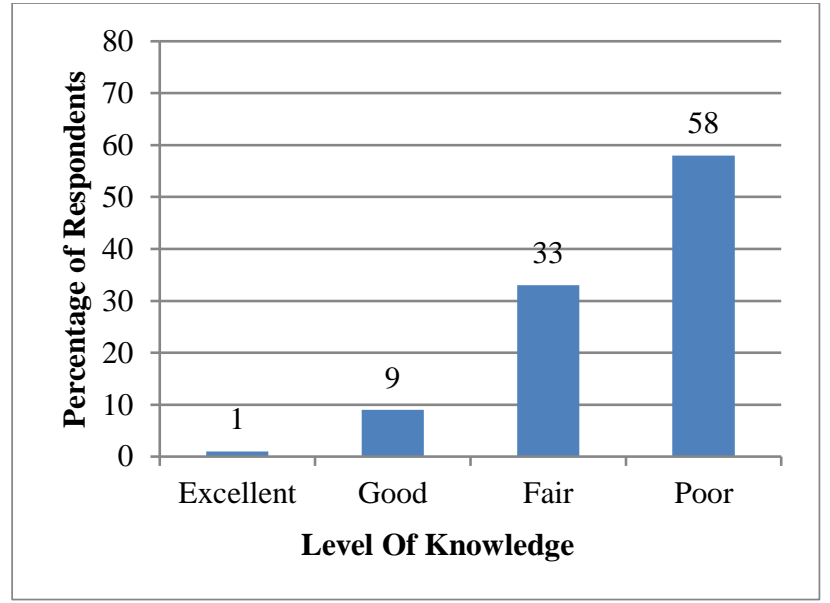

Figure 2: Knowledge among participants.

The response rate to practice based questions is depicted in Table 1. While assessing it was found that only 17 (9.24\%) have attended CME on haemovigilance. It was observed that $71(38.59 \%)$ of respondent had come across an adverse transfusion reaction while discharging their professional duties and $42(22.83 \%)$ had documented, but not reported while only $12(6.52 \%)$ have reported it to the haemovigilance centre.

\section{Table 1: Practice of transfusion reactions reporting.}

\begin{tabular}{|lll|}
\hline Practice related questions & $\begin{array}{l}\text { Yes } \\
\%\end{array}$ & $\begin{array}{l}\text { No } \\
\%\end{array}$ \\
\hline $\begin{array}{l}\text { Have you attended any CME's } \\
\text { /workshops/seminars on } \\
\text { haemovigilance? }\end{array}$ & 9.24 & 90.76 \\
\hline $\begin{array}{l}\text { Had you ever found any transfusion } \\
\text { reaction during your professional } \\
\text { practice? }\end{array}$ & 38.59 & 61.41 \\
\hline $\begin{array}{l}\text { Have you documented any transfusion } \\
\text { reaction? }\end{array}$ & 22.83 & 77.17 \\
\hline $\begin{array}{l}\text { Have you reported any transfusion } \\
\text { reaction to the haemovigilance } \\
\text { centre? }\end{array}$ & 6.52 & 93.47 \\
\hline
\end{tabular}

Table 2 shows the possible ways in improving transfusion reaction reporting. About 109 (59.24\%) HCP's was of the opinion that training will lead to a significant rise in reporting. Almost the same number of respondents $(57.07 \%)$ felt the need of CME's/ workshops/ seminars would also increase reporting. Other ways that will be beneficial, according to respondents were mandatory reporting system and availability of reporting forms in the ward. Table 3 depicts the factors discouraging transfusion reaction reporting. $57.61 \%$ respondents gave first preference to lack of knowledge on how and where to report. Another discouraging factor like lack of time to report, legal liability issues, difficult to decide a transfusion reaction has occurred or not were also quoted by the majority of respondents. 
Table 2: Possible ways in improving transfusion reaction reporting.

\begin{tabular}{|ll|}
\hline Possible ways to improve reporting & $\begin{array}{l}\text { Response } \\
\text { rate (\%) }\end{array}$ \\
\hline $\begin{array}{l}\text { Healthcare professionals should be } \\
\text { trained in reporting }\end{array}$ & 59.24 \\
\hline CME'S/workshops/seminars & 57.07 \\
\hline Making reporting compulsory & 47.28 \\
\hline $\begin{array}{l}\text { Keep the availability of transfusion forms } \\
\text { in the ward }\end{array}$ & 42.39 \\
\hline Make transfusion reporting easier & 41.30 \\
\hline Launching of a toll-free helpline no & 40.22 \\
\hline Development of mobile application & 26.09 \\
\hline $\begin{array}{l}\text { Remuneration of transfusion reaction } \\
\text { reporting }\end{array}$ & 14.13 \\
\hline Others & 11.41 \\
\hline
\end{tabular}

Table 3: Factors discouraging from reporting.

\begin{tabular}{|ll|}
\hline Factors discouraging from reporting & $\begin{array}{l}\text { Response } \\
\text { rate }(\%)\end{array}$ \\
\hline Lack of knowledge on how and where? & 57.61 \\
\hline Lack of time to report & 35.87 \\
\hline Legal liability issue & 29.35 \\
\hline $\begin{array}{l}\text { Difficult to decide transfusion reaction } \\
\text { has occurred or not }\end{array}$ & 25.54 \\
\hline Only Blood bank can report & 20.65 \\
\hline Fear of consequences & 15.76 \\
\hline Concern that report may be wrong & 15.22 \\
\hline Reporting of known reaction is not require & 13.04 \\
\hline $\begin{array}{l}\text { Single unreported case may not affect the } \\
\text { database }\end{array}$ & 12.50 \\
\hline No remuneration for reporting & 8.15 \\
\hline Others & 17.93 \\
\hline
\end{tabular}

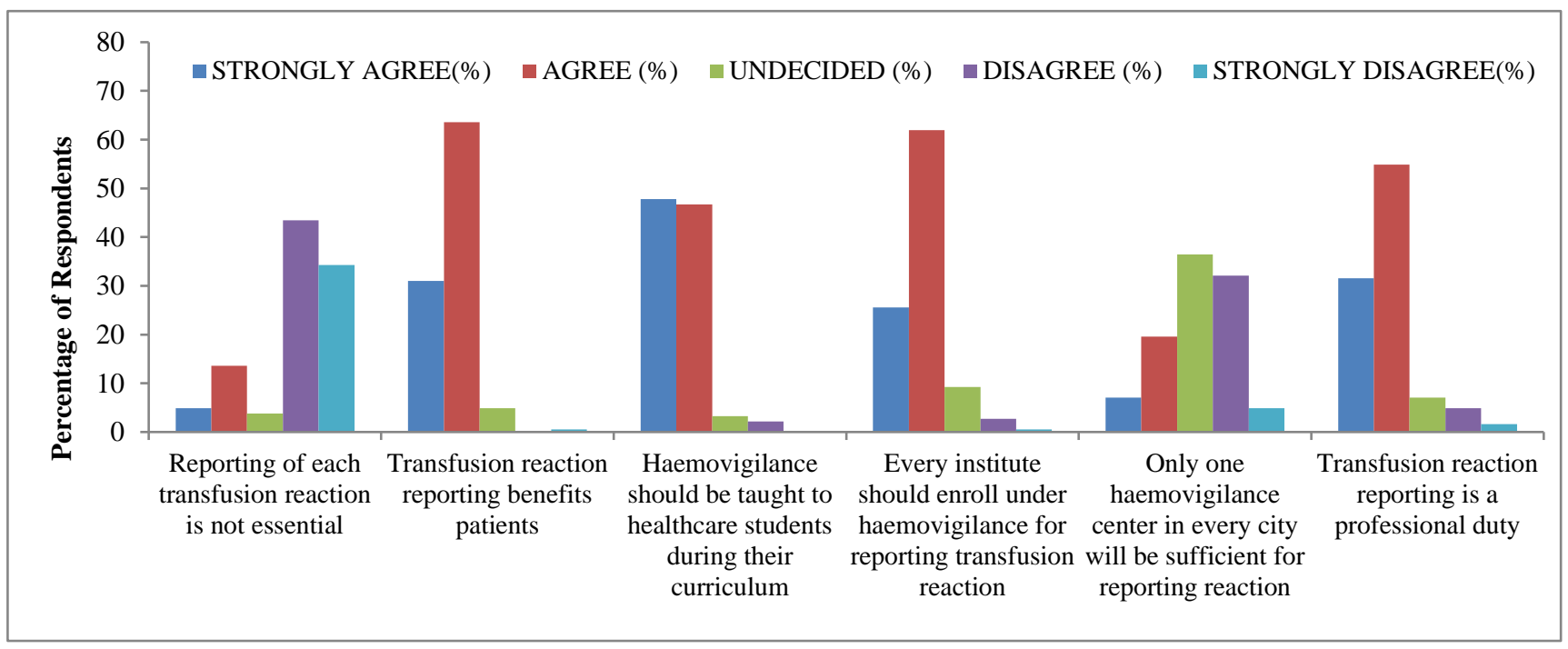

Figure 3: Attitude based statements towards reporting transfusion reactions.

\section{DISCUSSION}

The foremost thing to be noted in this type of studies is the responses of participants. Similar type of study conducted in Nagpur by Amit Date et al, reported a response rate of $75 \% .{ }^{11}$ Another study on knowledge on haemovigilance in South India by Narmada Sireesha et al, in 2015 found a response rate of $59 \% .{ }^{28}$ In this study, the response rate was found to be much higher $(93 \%)$. This is a good sign and reflects the curiosity amongst the various HCP towards a fairly new concept.

To the best of our knowledge this was the $1^{\text {st }}$ survey conducted in Nashik that evaluated the KAP of health care professionals regarding haemovigilance. The primary objective of this study was to evaluate the KAP of healthcare professionals about haemovigilance. The second primary objective was to find out the reasons for underreporting of transfusion reactions and also to find out the possible ways of improving reporting. The finding of the study uncovered many facts about the inadequate knowledge regarding haemovigilance and also showed the factors that may cause hindrance in reporting ATR.

HCP can play an important role in adverse transfusion reaction reporting because they are close to the patient and have good knowledge of symptoms of ATR. Given their unique position in recording adverse transfusion reaction, they are well placed to monitor patient responses. This is thus a logical reason to involve and encourage them to contribute in adverse transfusion reaction reporting system. 
The knowledge level about haemovigilance was found to be poor in this study (58\%), this that indicates a lot of HCP were not aware of it. Therefore, increasing awareness about haemovigilance program and transfusion reaction reporting is suggested.

Though it is known to the doctors that the medical practitioners like doctors, can report (29.35), the awareness that a nurse and pharmacist can do so is very low (71\%). This wrong belief is one of the main reasons for the underreporting of transfusion reactions. Active involvement of paramedical staff in spontaneous reporting of adverse transfusion reactions will go a long way in improving the reporting rates, since they are in closer contact with more patients for a longer duration than doctors. Results from this study showed that the majority of healthcare professionals had good knowledge regarding the concept of haemovigilance.

Healthcare professionals in the current study had very positive attitudes towards transfusion reaction reporting; many of them were of the belief that reporting of each transfusion reaction is essential and reporting them would have a positive impact on the patients. More than the half of the healthcare professionals in the present study agreed that the haemovigilance should be taught to health care students during their curriculum. So, to employ advantageously haemovigilance reporting system, effective measures should be considered by the regulatory authorities to introduce the same in the curriculum for healthcare students.

In the present study about $61.96 \%$ of healthcare professional agreed that every institute should be enrolled under haemovigilance. But, a similar study conducted by the Date A et al, produced much higher rate of $81.11 \%$ for framing the transfusion committee for their hospital. ${ }^{11}$ An overwhelming response of the healthcare professionals felt that transfusion reaction reporting is necessary and it is a professional obligation; this will give a potential approach for creating awareness and indulging the concept of haemovigilance for long term improvement of ATR.

This study strongly suggests that there is a great need to create awareness and to promote the reporting of ATR amongst healthcare professionals, which will lay a solid foundation for these budding healthcare professionals to be diligently involved in quality haemovigilance in their future practice. The haemovigilance practice found to be poor in this study. Very less of respondents (9.24\%) had attended any CME/workshops/seminars on haemovigilance which is much lower than the study conducted in Nagpur (20\%). ${ }^{11}$ About $38.59 \%$ respondents had identified and found ATR during the course of their practice; still those were not reported in most cases. This is in contrast to other survey in which the reporting of ATR was $22.22 \%$

While surveying the factors having a negative effect on reporting, the major constraint was lack of knowledge on 'how' and 'where' to report the adverse transfusion reactions. In addition to not knowing where and how to report, one third $(35.87 \%)$ of respondents implicated the lack of time as a major issue for underreporting. Some of the others barriers in underreporting are the misbeliefs that only blood banks can report ATR, concerns that reporting may be wrong or a single unreported case may not affect the database. Another barrier for ATR reporting that was mentioned by healthcare professionals was having difficulty in identifying whether a transfusion reaction has occurred or not. These observations suggest that raising awareness about ATR and providing on-going training could help in increasing ATR reporting. Previously published studies reported similar constraints and in addition, they reported concerns with regard to apprehension regarding sending inappropriate form which was also associated with underreporting.

While assessing the possible ways to improve transfusion reaction reporting maximum HCP $(59.24 \%)$ were of the opinion that training they will lead to a significant rise in reporting. Other opted ways of improving reporting were conducting CME's/seminars $(90.76 \%)$, easier reporting system $(41.30 \%)$ were quoted. Our findings were almost similar to the study conducted by Date A et al, which also showed that conducting $\mathrm{CME}$, training $\mathrm{HCP}$, making reporting easier will significantly improve reporting. ${ }^{11}$

Thus, if the knowledge is improved, the perception towards reporting will also be altered and will ultimately lead to the increased practice of reporting towards haemovigilance. This is an avenue where there is ample scope of improvement and needs to be certainly addressed. About half of the respondents (47.28\%) felt that reporting should be made compulsory which is a positive sign of healthcare professionals towards the importance of adverse transfusion reaction monitoring and the need to increase its presence as well as functional ambit. Apart from these major suggestions, the majority of the healthcare professionals $(42.39 \%)$ believe that the availability of reporting forms in the ward in their practice can also improve the reporting system which was as close as $50 \%$ in an Amit Date et al study. ${ }^{11}$ Launching a toll free helpline number and also development of mobile application were the least preferred methods to aid in improving transfusion reporting.

\section{Recommendations}

The authors findings provide a basis to develop and implement strategies to improve adverse transfusion reporting. Though positive attitude was seen in general, there were considerable limited practices towards ATR reporting in the HCP, Nasik. This call for the need of Interventional educational programs, collaboration between academic and health authorities is a key to achieve this goal. It is necessary to offer continuous ATR related ventures until we reach the point that the voluntary reporting of Adverse Transfusion Reactions becomes 
conventional and habitual among the healthcare professionals.

\section{ACKNOWLEDGEMENTS}

Authors would like to thank all the participants who responded promptly to the questionnaires.

Funding: No funding sources

Conflict of interest: None declared

Ethical approval: The study was approved by the Institutional Ethics Committee

\section{REFERENCES}

1. World Health Organization. A guide to establishing a national haemovigilance system. Available at: http://apps.who.int/iris/bitstream/10665/250233/1/97 89241549844-eng.pdf

2. Gupta M, Kumar R, Gupta S, Kaur A. Acute transfusion reactions encountered in patients at a tertiary care centre in Punjab. Natl Med J India. 2015;28(1):8-11.

3. Bisht A. Haemovigilance Programme of IndiaOrganization structure. 2014. Available from: http://www.ihnorg.com/wpcontent/uploads/2014/01/ Haemovigilance-Programme-of-India-by-AkankshaBisht.pdf.

4. Wiersum-Osselton J. Hemovigilance: is it making a difference to safety in the transfusion chain? Netherland: 2013:1-155.

5. Boparai J, Singh S. Hemovigilance: A new beginning in India. Int J Appl Basic Med Res. 2015;5(3):200-2.

6. Sreekumar P, Pramod Kumar T, Sarathi G, Gupta D. Haemovigilance-roles and global status in transfusion safety: a review. IRJP. 2016;7(12):5-7.

7. Sreekumar P, Kumar T, Sarathi G, Gupta D. Haemovigilance in India - A Milestone in Transfusion Safety. Int J Health Sci Res. 2017;7(2):310-5.

8. Singh S, Bisht A, Singh S, Kalaiselvan V, Chopra V, Kumari P, et al. Review on haemovigilance practice in India. WJPPS. 2015;4(12):350-7.

9. Mukherjee S, Maiti R. Haemovigilance: A Current Update in Indian Perspective. J Clin Diagn Res. 2016;10(11):EE05-EE09.

10. World Health Organisation. AIDE-MEMOIRE. National Haemovigilance System; 2015.

11. Date A, Dashputra A, Borkar A. Knowledge attitude and practice of haemovigilance among doctors in tertiary care hospital in Nagpur, Maharashtra, India. IJBCP. 2017;5(3):788-93.

12. Bisht A, Gupta S, Singh S. Transfusion Reaction Reporting Culture in Hemovigilance Program of India since its Inception. JRFHHA. 2015;3(2):69-70.

13. National Institute of Biologicals. Haemovigilance Newsletter. Available from: http://emedinews.in/ 2015/IJCPebook/haemovigilance/files/haemovigilanc e\%20newsletter\%20vol\%20no.\%203,\%20issue\%206, $\% 20$ julydecember\%202015_ctc\%20(1).pdf.
14. Py J, Durieux S, Barnoux M, Sapey T. Delayed adverse reactions to blood donation: From haemovigilance data to specific studies. Transfus Clin Biol. 2016;23(4):233-9.

15. Beckers EA, Dinkelaar RB, Boekhorst PA, van Ingen HE, van Rhenen DJ. Reports of transfusion incidents: experiences from the first year of hemovigilance in the region of the former ZWN blood bank in Rotterdam. Ned Tijdschr Geneeskd. 2003;147(31):1508-12.

16. Sinha R, Rai P, Dey A. A study of transfusion related adverse events at a tertiary care center in central india: a retrospective evaluation. J Med Sci Health. 2016;2(3):6-12.

17. Patil S, Patil L, Chavan S. Acute transfusion reactions in intensive care unit: a retrospective Study. IOSRJDMS. 2017;16(1):73-5.

18. The Kap Survey model - Knowledge attitude and practices. ISSUU, 2015. Available from: https://issuu.com/medecinsdumonde/docs/47-thekap-survey-model-knowledge-a/13.

19. Mwangi J, Kimani D, Odour M. Approaches to advancing blood safety through haemovigilance: A review. East Afr Med J. 2009;86:S93-S97.

20. Dahourou H, Tapko J, Nébié Y, Kiénou K, Sanou M, Diallo $\mathrm{M}$, et al. Implementation of hemovigilance in Sub-Saharan Africa. Transfus Clin Biol. 2012;19(1):39-45.

21. Giampaolo A, Piccinini V, Catalano L, Abbonizio F, Hassan $\mathrm{H}$. The first data from the haemovigilance system in Italy. Blood Transfus. 2007;5(2):66-74.

22. Basavaraju S, Lohrke B, Pitman J, Pathak S, Meja B, Shiraishi R, et al. Knowledge and barriers related to reporting of acute transfusion reactions among healthcare workers in Namibia. Transfus Med. 2013;23(5):367-9.

23. Vartak U, Shewale R, Vartak S, Faizal F, Majethia N. Adverse Reactions of Blood Transfusion: A Study in a Tertiary care Hospital. IJSS. 2016;4(2):90-4.

24. Gupta SK, Nayak RP, Shivaranjani R, Vidyarthi SK. A questionnaire study on the knowledge, attitude, and the practice of pharmacovigilance among the healthcare professionals in a teaching hospital in South India. Perspect Clin Res. 2015;6(1):45-52.

25. Datta S, Sengupta S. An evaluation of knowledge, attitude, and practice of adverse drug reaction reporting in a tertiary care teaching hospital of Sikkim. Perspect Clin Res. 2015;6(4):200-6.

26. Sireesha N, Reddy P, Sravani J, Rani S, Rathinavelu M. Assessment of Healthcare Professional Awareness towards Haemovigilance (HvPI) Programme of India in South India. IOSR-JPBS. 2015;10(5):13-7.

Cite this article as: Shivgunde PP, Besekar SM, Bhojwani KM, Bhojwani DG. Knowledge, attitude and practice of haemovigilance amongst healthcare professionals in Nashik, Maharashtra, India. Int J Basic Clin Pharmacol 2018;7:986-91. 